\title{
Kudos and Renaissance of s-Block Metal Chemistry
}

\author{
Sven Krieck ${ }^{1}$ and Matthias Westerhausen ${ }^{1, *}$ \\ Institute of Inorganic and Analytical Chemistry, Friedrich Schiller University Jena, Humboldtstrasse 8, \\ D-07743 Jena, Germany; sven.krieck@uni-jena.de \\ * Correspondence: m.we@uni-jena.de; Tel.: +49-3641-9-48110 \\ Academic Editor: Peter W. Roesky \\ Received: 13 March 2017; Accepted: 21 March 2017; Published: 21 March 2017
}

\begin{abstract}
In recent years, the organometallic and coordination chemistry of the alkali and alkaline earth metals has experienced tremendous progress to tackle the needs of today's society. Enhanced ecological awareness and global availability favor research on the chemistry of the essential s-block metals. Nowadays, the s-block metals are conquering new chemical fields based on sophisticated theoretical and preparative achievements. Recent investigations show a huge impact of the s-block elements on stoichiometric and catalytic processes.
\end{abstract}

Keywords: s-block metals; catalysis; Grignard reagents; alkali metals; alkaline earth metals

The s-block metals subsume the elements of the first two groups of the periodic table-the alkali and alkaline earth metals. The non-radioactive elements were all discovered by the middle of the 19th century [1] (Table 1), initiating a profound s-block metal-based chemistry with a very long tradition. Generally, the toxicity is low and highly toxic congeners are limited to the radioactive metals and beryllium [2], justifying the underrepresented extent of their chemistry.

Table 1. Year of discovery [1] and selected properties [3] of the s-block metals (radii are given in pm; cation radii are given for six-coordinate ions).

\begin{tabular}{|c|c|c|c|c|c|c|}
\hline & $\begin{array}{c}\text { Year of } \\
\text { Discovery }\end{array}$ & $\begin{array}{l}\text { Allred-Rochow } \\
\text { Electronegativity }\end{array}$ & $\begin{array}{l}\text { Atomic } \\
\text { Radius }\end{array}$ & $\begin{array}{l}\text { Cation } \\
\text { Radius }\end{array}$ & $\begin{array}{l}\text { Element } \\
\text { Essential }\end{array}$ & $\begin{array}{c}\text { Toxicity of } \\
\text { Element }\end{array}$ \\
\hline $\mathrm{Li}$ & 1817 & 0.97 & 157 & 90 & - & + \\
\hline $\mathrm{Na}$ & 1807 & 1.01 & 191 & 116 & + & - \\
\hline $\mathrm{K}$ & 1807 & 0.91 & 235 & 152 & + & - \\
\hline $\mathrm{Rb}$ & 1861 & 0.89 & 250 & 166 & - & + \\
\hline $\mathrm{Cs}$ & 1860 & 0.86 & 272 & 181 & - & - \\
\hline $\mathrm{Fr}$ & 1939 & 0.86 & 270 & 194 & - & +++ \\
\hline $\mathrm{Be}$ & 1797 & 1.47 & 111.3 & 59 & - & +++ \\
\hline $\mathrm{Mg}$ & 1755 & 1.23 & 159.9 & 86 & + & - \\
\hline $\mathrm{Ca}$ & 1808 & 1.04 & 197.4 & 114 & + & - \\
\hline $\mathrm{Sr}$ & 1790 & 0.99 & 215.1 & 132 & - & - \\
\hline $\mathrm{Ba}$ & 1808 & 0.97 & 224 & 149 & - & + \\
\hline $\mathrm{Ra}$ & 1898 & 0.97 & 230 & 162 & - & +++ \\
\hline
\end{tabular}

The organic and coordination chemistry of these highly electropositive metals is dominated by mainly ionic bonds and the salt-like nature of their compounds. The most electropositive non-radioactive element, cesium, has an Allred-Rochow electronegativity of 0.86 [3] (Table 1). Generally, these elements are redox inert and oxidation states of +- I and + II of the alkali and alkaline earth metals, respectively, are maintained throughout the chemical transformations; exceptions include the thermally stable magnesium(I) [4] and calcium(I) complexes [5]. Polar organometallic chemistry has recently gained tremendous interest due to a paradigm shift in the principles and practice, widening the tasks and applications of these reagents [6]. 
Organomagnesium compounds have been known for more than a century, and in 1912, Victor Grignard was awarded with the Nobel Prize for the achievement of introducing organomagnesium halides, the so-called Grignard reagents, to organic and organometallic chemistry [7]. Still today, the coordination and organic chemistry of magnesium offers many facets for future tasks [8-11]. A few years after the discovery of the Grignard reagents, organolithium chemistry was developed by the research groups of Gilman [12] and Schlenk [13] and long lasting, extensive research efforts now allow us to understand the chemistry of these light s-block metals [14]. The chemistry of the heavier congeners poses severe challenges due to diverse reasons. The salt-like nature of the organometallics of the heavy alkali metals leads to solubility problems in common organic solvents. In addition, the strongly heteropolar nature of bonds to non-metallic p-block elements increases the nucleophilic character of the anions. This enhanced reactivity eases side-reactions with solvents and substrates (such as ligand coordination, aggregation, solvent and ligand degradation, as well as Wurtz-type coupling reactions) and hampers the straightforward direct synthesis. The heavy alkaline earth metals are high-melting elements and activation is required to reduce the discrepancy between the inertness of the metal itself and the enormous reactivity of its organometallics.

In very recent years, the interest in the chemistry of the s-block metals has gained tremendously in importance due to increased environmental and ecological awareness and, hence, the need for non-toxic reagents with a broad diversity of properties with respect to availability, reactivity, applicability, and costs has become evident. This fact led to the increasing impact of this chemistry in all fields of chemistry (Figure 1), especially in organometallic and catalytic applications $[15,16]$. Thus, the delayed development of a sophisticated organic [17] and coordination chemistry of calcium [18] led to the nickname of "sleeping beauty" for this dormant element [18,19]. Lithium (and to a lesser extend sodium and magnesium) will become the foundation for car batteries, ensuring electric-based transport and, hence, the demand (as well as the price) will increase significantly. Recent studies have elucidated the suitability of magnesium hydrides as storage materials for hydrogen, one of the future energy carriers. In the recent past, increasing efforts have been undertaken to develop a sophisticated chemistry of these elements [19-21]. The chemistry of methanediides [22] and the relevance of secondary interactions [23], discussed in this Special Issue, may be viewed as representative examples.

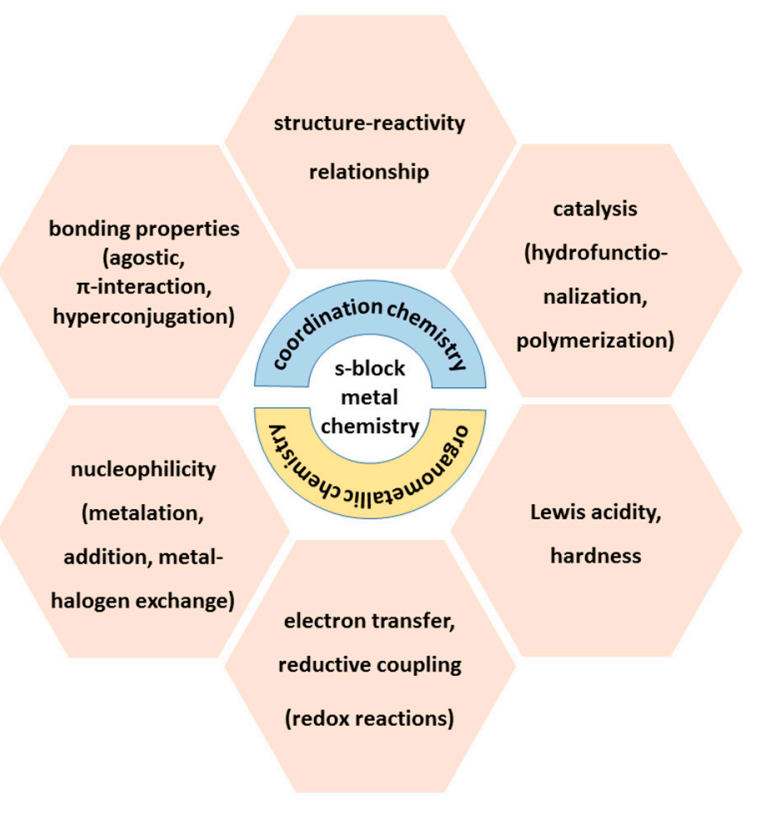

Figure 1. Representation of the broadness and importance of s-block metals in coordination and organometallic chemistry, covering unique structures and bonding properties as well as applications in stoichiometric and catalytic reactions. 
In contrast to lithium, the heavier homologous elements, sodium and potassium as well as calcium, are globally abundant, easily available, inexpensive and of low toxicity. Whereas the mining and salt production of these metals (e.g., rock salt, lime and gypsum) are routinely performed in industrial processes in very large scale, the organic and organometallic as well as coordination chemistry of the heavier alkali and alkaline earth metals is now awakening and diverse research groups are focusing on specific aspects of the demanding chemistry of s-block metal compounds. On the one hand, the electropositive nature of the metals increases toward the heavier congeners (decreasing electronegativity), leading to the enhanced heteropolar nature of bonds to carbon, nitrogen and oxygen. On the other hand, Lewis acidity is related to the charge-to-radius (or charge-to-surface) ratio with cesium being the softest element in the periodic table. Softness of an element or ion is directly related to its polarizability and compressibility. Thus, lithium and calcium have very similar electronegativity values and, hence, comparable bond polarities but a significantly enhanced Lewis acidic character of the calcium ions can be expected. This consideration might emblematize the reason for stronger bonds to even very weak Lewis bases such as $\sigma$-bonds (agostic bonds) and $\pi$-electron density ( $\pi$-interactions).

Future tasks related to the chemistry of these s-block organometallics include stability and reactivity [17], catalysis and stoichiometric conversions [18,21], Lewis acidity and nucleophilicity [24]. Quantum chemical calculations are valuable tools to elucidate the agostic and $\pi$-interactions between the s-block metal ions and multiple bonds $[25,26]$. Isoelectronic ion pairs such as $\mathrm{Na}^{+} / \mathrm{Mg}^{2+}, \mathrm{K}^{+} / \mathrm{Ca}^{2+} / \mathrm{Sc}^{3+}, \mathrm{Rb}^{+} / \mathrm{Sr}^{2+} / \mathrm{Y}^{3+}$, and $\mathrm{Cs}^{+} / \mathrm{Ba}^{2+} / \mathrm{La}^{3+}$ allow one to deduce the influence of electronegativity, size and hardness on reactivity and bonding parameters. The isoelectronic relations demonstrate that the heavy alkaline earth metals calcium, strontium and barium have intermediate positions between the alkali metal ions (highly electropositive, polarizable, highly ionic character) and the early transition metal ions (highly Lewis acidic, d-orbital participation, catalytic reactivity). This fact interrelates the chemistry of these heavy alkaline earth metals to the catalytic activity of complexes of the scandium group.

Understanding the diverse characteristics of these highly reactive compounds will expand the knowledge on reactivity and property; this will enable one to commonly tackle future challenges related to these highly polar organometallic and coordination compounds and catalysts that often have unique reaction patterns and mechanisms.

Conflicts of Interest: The authors declare no conflict of interest.

\section{References}

1. Emsley, J. The Elements; Clarendon Press: Oxford, NY, USA, 1989.

2. Naglav, D.; Buchner, M.R.; Bendt, G.; Kraus, F.; Schulz, S. Off the beaten track-A hitchhiker's guide to beryllium chemistry. Angew. Chem. Int. Ed. 2016, 55, 10562-10576. [CrossRef] [PubMed]

3. Holleman, A.F.; Wiberg, E.; Wiberg, N. Lehrbuch der Anorganischen Chemie (Holleman-Wiberg), 102nd ed.; de Gruyter: Berlin, Germany, 2007.

4. Stasch, A.; Jones, C. Stable Dimeric Magnesium(I) Compounds: From chemical landmarks to versatile reagents. Dalton Trans. 2011, 40, 5659-5672. [CrossRef] [PubMed]

5. Krieck, S.; Görls, H.; Yu, L.; Reiher, M.; Westerhausen, M. Stable "inverse" sandwich complex with unprecedented organocalcium(I): crystal structures of $\left[(\text { thf })_{2} \mathrm{Mg}(\mathrm{Br})-\mathrm{C}_{6} \mathrm{H}_{2}-2,4,6-\mathrm{Ph}_{3}\right]$ and [(thf) $\left.)_{3} \mathrm{Ca}\left\{\mu-\mathrm{C}_{6} \mathrm{H}_{3}-1,3,5-\mathrm{Ph}_{3}\right\} \mathrm{Ca}(\text { thf })_{3}\right]$. J. Am. Chem. Soc. 2009, 131, 2977-2985. [CrossRef] [PubMed]

6. Hevia, E.; Mulvey, R. Towards a paradigm shift in the principles and practice of polar organometallic chemistry (EPSRC Fund). Available online: https://pure.strath.ac.uk/portal/en/projects/towards-aparadigm-shift-in-the-principles-and-practice-of-polar-organometallic-chemistry(5f1b83e5-44b1-49938de8-4ea484510c7d).html (accessed on 10 March 2017).

7. Seyferth, D. The Grignard reagents. Organometallics 2009, 28, 1598-1605. [CrossRef]

8. Westerhausen, M.; Krieck, S. Magnesium. Available online: http://www.aktuelle-wochenschau.de/ main-navi/archiv/chemie-der-elemente-2016/kw51-magnesium.html?gid=108266Andreas (accessed on 10 March 2017). 
9. Benischke, A.D.; Ellwart, M.; Becker, M.R.; Knochel, P. Polyfunctional zinc and magnesium organometallics for organic synthesis: Some perspectives. Synthesis 2016, 48, 1101-1107.

10. Martínez-Martínez, A.J.; O'Hara, C.T. Lithium, sodium, and potassium magnesiate chemistry: A structural overview. Adv. Organomet. Chem. 2016, 65, 1-46.

11. Harrison-Marchand, A.; Mongin, F. Mixed AggregAte (MAA): A single concept for all dipolar organometallic aggregates. 1. Structural data. Chem. Rev. 2013, 113, 7470-7562. [CrossRef] [PubMed]

12. Eisch, J.J. Henry Gilman: American pioneer in the rise of organometallic chemistry in modern science and technology. Organometallics 2002, 21, 5439-5463. [CrossRef]

13. Seyferth, D. Alkyl and aryl derivatives of the alkali metals: Strong bases and reactive nucleophiles. 2. Wilhelm Schlenk's organoalkali-metal chemistry. The metal displacement and the transmetalation reactions. Metalation of weakly acidic hydrocarbons. Superbases. Organometallics 2009, 28, 2-33. [CrossRef]

14. Capriati, V.; Perna, F.M.; Salomone, A. "The great beauty" of organolithium chemistry: A land still worth exploring. Dalton Trans. 2014, 43, 14204-14210. [CrossRef] [PubMed]

15. Smith, J.D. Organometallic compounds of the heavier s-block elements-What next? Angew. Chem. Int. Ed. 2009, 48, 6597-6599. [CrossRef] [PubMed]

16. Ritter, S.K. Calcium's awakening. Chem. Eng. News 2011, 89, 49-51. [CrossRef]

17. Westerhausen, M.; Koch, A.; Görls, H.; Krieck, S. Heavy Grignard reagents: Synthesis, physical and structural properties, chemical behavior and reactivity. Chem. Eur. J. 2017, 23, 1456-1483. [CrossRef] [PubMed]

18. Harder, S. From limestone to catalysis: Application of calcium compounds as homogeneous catalysts. Chem. Rev. 2010, 110, 3852-3876. [CrossRef] [PubMed]

19. Harder, S. (Ed.) Alkaline-earth Metal Compounds: Oddities and Applications; Springer: Heidelberg, Germany, 2013.

20. Hanusa, T.P. (Ed.) The Lightest Metals: Science and Technology from Lithium to Calcium; Wiley: Chichester, UK, 2015.

21. Hill, M.S.; Liptrot, D.J.; Weetman, C. Alkaline earths as main group reagents in molecular catalysis. Chem. Soc. Rev. 2016, 45, 972-988. [CrossRef] [PubMed]

22. Feichtner, K.S.; Gessner, V.H. Synthesis and characterization of a sulfonyl- and imino-phosphorylfunctionalized methanide and methanediide. Inorganics 2016, 4, 40. [CrossRef]

23. Roşca, S.C.; Roueindeji, H.; Dorcet, V.; Roisnel, T.; Carpentier, J.F.; Sarazin, Y. $\mathrm{K}^{+} \ldots \mathrm{C}_{\pi}$ and $\mathrm{K}^{+} \ldots \mathrm{F}$ non-covalent interactions in $\pi$-functionalized potassium fluoroalkoxides. Inorganics 2017, 5, 13. [CrossRef]

24. Leboeuf, D.; Gandon, V. Carbon-carbon and carbon-heteroatom bond-forming transformations catalyzed by calcium(II) triflimide. Synthesis 2017, 49, 1500-1508. [CrossRef]

25. Dufrois, Q.; Vendier, L.; Etienne, M. $\alpha$-CC agostic structures and aggregation diversity in cyclopropyllithium derivatives. Chem. Commun. 2016, 52, 6781-6784. [CrossRef] [PubMed]

26. Roşca, S.C.; Dinoi, C.; Caytan, E.; Dorcet, V.; Etienne, M.; Carpentier, J.F.; Sarazin, Y. Alkaline earth-olefin complexes with secondary interactions. Chem. Eur. J. 2016, 22, 6505-6509. [CrossRef] [PubMed]

(C) 2017 by the authors. Licensee MDPI, Basel, Switzerland. This article is an open access article distributed under the terms and conditions of the Creative Commons Attribution (CC BY) license (http://creativecommons.org/licenses/by/4.0/). 